\title{
Statins: perspectives in Cancer Therapeutics
}

\section{Laurent CORCOS \& Catherine LE JOSSIC-CORCOS}

INSERM U1078-ECLA and SFR-ScInBioS, Université Européene de Bretagne, Université de Bretagne Occidentale, Faculté de médecine, 22 avenue Camille Desmoulins, 29200 Brest, France

\section{Corresponding author : Laurent CORCOS}

Email : laurent.corcos@inserm.fr

\begin{abstract}
Virtually any cell type in a mammalian organism uses Acetyl CoA to yield mevalonate, through the activity of the 3-hydroxy-3-methyl-glutaryl-CoA (HMG-CoA) reductase enzyme and, ultimately, cholesterol. Statins have long and quite successfully been used as cholesterol lowering drugs. They reversibly inhibit the HMG-CoA reductase activity, which is rate limiting in the early steps of the cholesterol synthesis pathway. In addition to these effects, it has also been amply shown that statins may efficiently trigger cancer cell apoptosis, making them a plausible therapeutic option for the treatment of cancer. Whether statins may prevent from cancer occurrence is a matter of debate and an unanswered question, but no doubt experimental models have clearly demonstrated the potential of statins as direct cytotoxic agents, which can reduce tumor development or metastasis spreading, even more so when combined to cytotoxic drugs. Until now, however, only few data in humans support the idea that statins could rightfully enter the contingent of anticancer drugs. Nevertheless, at times where cancer cells metabolism is getting very much revisited, the mevalonate pathway has recently been reported as truly oncogenic, bringing upfront the attractive possibility to see mevalonate pathway blunting agents, such as statins, join the wealth of anticancer drugs.
\end{abstract}

Key words: statins, cholesterol, metabolic syndrome, treatment, prevention, digestive cancer 


\section{1-Introduction}

\section{1-The mevalonate pathway}

The so-called mevalonate pathway (Figure 1) initiates with the enzymatic conversion of acetoacetyl-CoA into 3-hydroxy-3-methylglutaryl-CoA (HMG-CoA) catalyzed by the HMG-CoA synthase [1]. HMG-CoA is next converted into mevalonate in a rate-limiting reaction catalyzed by the HMG-CoA reductase. Ensues a series of 27 biochemical reactions that lead to cholesterol synthesis. Importantly, this pathway also generates prenyl carbon chains, farnesyl pyrophosphate (FPP) and geranyl geranyl pyrophosphate (GGPP), which are mandatorily added, in a post-translational fashion, to the C-terminus of several proteins that contain a CAAX motif [1], [2]. This prenylation reaction allows proteins, such as small GTPases from the Ras and Rho families, to anchor to the inner plasma membrane and acquire their enzymatic activities. Hence, a restriction in activity of the mevalonate pathway imposed, for example, by a blockage in the very early steps, results in shortage of FPP and GGPP, thereby preventing these GTPases from gaining functional activity. A schematic summary of the signaling pathways is shown in Figure 2. Other effects induced by blunting the mevalonate pathway include, in addition to cholesterol restriction, a drop in the production of active dolichol, Heme A or ubiquinone that fulfill important functions in protein glycosylation or cell respiration.

\section{2-Statins, pharmacology and mechanism of action}

Statins have been developed from natural compounds isolated from fungi. Mevastatin (compactin, ML-236B) was purified from Penicillium citrinum and lovastatin (Mevinolin, Monacolin K) from Aspergillus terreus [3]. Later, synthetic statins were developed, including fluvastatin, simvastatin, or pravastatin. Remarkably, the Ki value for inhibition of the HMGCoA reductase is $1 \times 10^{-9} \mathrm{M}$, whereas the $\mathrm{Km}$ Value for the enzyme and its natural substrate HMG-CoA is $1 \times 10^{-5} \mathrm{M}$. Mevastatin was then shown to be highly active at inhibiting sterol synthesis in live human cells at nanomolar concentrations [4, 5]. In addition, micromolar concentrations inhibited cell growth and altered cell morphology, which was reversed by the addition of small amounts of mevalonate, the product of the HMG-CoA reductase enzyme, but not cholesterol, the end product of the pathway [6]. The selection of mevastatin resistant hamster cells showed that the HMG-CoA reductase gene had been amplified, and 
the protein stabilized [7]. This and further experiments led to the isolation of the gene. As one major consequence of the activity of the mevalonate pathway, several cellular proteins are modified through the post-translational addition of prenyl (FPP or GGPP) groups, including p21 ${ }^{\text {ras }}$ GTPase or lamin B [8-11], suggesting that the activity of these proteins could be strongly dependent on that of the pathway. Since that time, numerous studies have addressed the myriad of consequences of statin treatment in various models, including cells in culture and laboratory animals.

Important species to species differences in the activity of statins could, however, occur between rodents and humans, who exhibit a unique profile of drug metabolizing enzymes, making it hazardous to transpose data obtained in rodents directly to humans. In humans, statins are subject to various metabolic transformations that maybe associated, collectively, with transient liver dysfunction in a modest $1 \%$ of the cases [12]. Indeed, a few cases of liver injury have been reported, with atorvastatin and mevastatin [13]. Atorvastatin, lovastatin and simvastatin are metabolized by CYP3A4, fluvastatin and rosuvastatin by CYP2C9, and pravastatin - the only water-soluble statin - undergoes sulfation. In addition, these hepatic first pass metabolisms lead to production of either active (atorvastatin, lovastatin, simvastatin) or inactive (fluvastatin, pravastatin) metabolites. All statins, but fluvastatin, are substrate of drug transporter proteins. Taken together, these metabolic characteristics of statins make these compounds prone to engage in drug-drug interactions, especially CYPdependent interactions. Nevertheless, drug-drug interactions - involving statins and cyclosporine, fibrates or niacin among several others - have been reportedly rare. Nevertheless, a few fatal cases ( 0.15 deaths per million) resulting from rhabdomyolysis have been registered, which led to the removal of cerivastatin from the market. These data show that statins may be harmful, but at rather low frequency, in the general population undergoing statin therapy to treat high cholesterol levels. In addition, dose-escalating regimen in short time treatments, once administered to cancer patients, showed good tolerance, up to $415 \mathrm{mg} / \mathrm{m}^{2}$ lovastatin, and peak plasma concentrations as high as $12.3 \mu \mathrm{M}$ lovastatin [14].

A major discovery was that from the Brown and Goldstein Laboratory who unraveled the feedback mechanism evoked by statins on the mevalonate pathway. Indeed, they elegantly demonstrated that the endoplasmic reticulum was able to perceive a drop in cholesterol 
concentration, thereby stimulating back a rise in the activity of the pathway. This is operated through the release of the Sterol Response Element Binding proteins (SREBP), from the ER membrane, their proteolysis in the Golgi apparatus, giving rise to $\mathrm{N}$-terminal fragments that then enter the nucleus to serve as transcriptional activators of virtually all genes from the mevalonate pathway [1]. This mechanism regulates the balance between cholesterol intake via Low Density Lipoproteins and endogenous synthesis.

An important consequence of blunting the mevalonate pathway with statins is the blockage of the prenylation of small GTPases, including Ras, Rho, Rac or cdc42. Because these proteins are involved in the control of cell division, shape or motility, they play major roles in cancer. In addition, they may even gain proliferative potential through acquired activating mutations. Hence, when $\mathrm{p} 21^{\text {ras }}$ farnesylation was shown to be strongly decreased in response to statins, it came as a real hope that statins, or else farnesyl transferase inhibitors, could be used to treat cancer.

\section{2-Cancer, epidemiological data}

\section{1-Incidence of cancer}

Statins are widely used to lower cholesterol levels, and millions of people are treated worldwide annually. Hence, several very large cohorts of patients have been followed over the years, demonstrating the highly beneficial impact of statins on cardiovascular diseases. These cohorts were also used to question the possible impact of statins on cancer occurrence. However, because these studies were conducted in a retrospective manner, the conclusions might not be rightfully interpreted or even be erroneous. Nevertheless, a large amount of data was collected. In essence, either one of two conclusions were attained. In several studies, statins could prevent cancer occurrence, by up to $50 \%$, or, in others, no protective effects were registered. Nevertheless, it now seems that statins may be more beneficial than detrimental in acting on cancer.

Originally, the Prosper [15] study had suggested that pravastatin could increase cancer incidence in subjects over 75. However, this was not confirmed in further studies, which showed no increase [16]. Among 10000 subjects from the Heart Protection Study, there was no difference in death numbers among subjects taking simvastatin compared to placebo 
[17]. In patients under statin therapy, there was no relationship between the level of LDL-C reduction and the risk of cancer, but a surprising inverse relationship between achieved LDLC levels and rates of newly diagnosed cancer [18]. In addition, large studies revealed no differences between the statin and the placebo groups from the Cholesterol Treatment Trialist studies $[19,20]$. Furthermore, statins - taken for over one year - were not associated with increased risk for 13 distinct cancer types [21]. This study also showed that untreated hyperlipidemia was associated with slightly higher incidence of colon, bladder and prostate cancer. Other epidemiological studies did not detect modified cancer risk levels in response to statins $[22,23]$. As reviewed recently, no beneficial or detrimental effects of statin usage in cancer incidence were recorded for prostate, breast, colorectal, lung, bladder, renal cell, or pancreatic cancer, but potential protective effects were observed for melanoma, endometrial cancer and non-Hodgkin lymphoma [13].

Overall, the apparent discrepancies between studies may originate from differences in the analytical methods and populations, lack of clear dose or duration of statin exposure, which was often relatively short with respect to the time required to develop cancers. In addition, and most importantly, the vast majority of studies was retrospective, and was not designed to address the question of cancer incidence, but the effect on cardiovascular diseases [24]. Several additional factors of variation in the sensitivity to statins have been recorded. HMGCR gene SNP alleles dictate the structure, and hence the activity, of the enzyme. Indeed, depending on several SNPs in the gene, the enzyme, which is normally assembled as a homotetramer, may be composed of full-length monomers and truncated monomers due to the SNP-dependent alternative splice product devoid of exon 13 that encodes a subdomain important for statin interaction [25]. In addition, several very elegant and recent studies have demonstrated, in experimental models of breast cancer, that the mevalonate pathway is a true oncogenic pathway, often overactive in cancer cells [26]. Furthermore, mutant forms of p53 gain a novel function in recruiting SREBP transcription factors onto the genes from the mevalonate pathway, thereby amplifying its activity [27]. These important experimental data strongly reinforce the concept that blunting the pathway is a relevant strategy to combat cancer. Furthermore, breast cancer stem cells can also be sensitized by the use of statins, as a result of the high activity of the mevalonate pathway [28].

An early study showed that lovastatin reduced slightly cancer incident cases (14 cases in the 
lovastatin group vs 21 cases in the reference group) [29]. Other studies showed $20-28 \%$ reduction of cancer incidence by statins $[22,30]$. Reduced incidence of melanoma and colon cancer was also reported [22, 31, 32]. In a land marking paper by Poynter [33], it was observed that an Israeli cohort of subjects under statin therapy for 5 years showed an impressive 50\% reduction in colon cancer cases. However, a very large survey of 132136 men and women did not show any such reduction in colon cancer incidence [34] [35] [10, 36, 37]. A series of studies in independent population sets showed that cancer incidence was reduced by statins, including colon [35], liver [38], [35], breast, skin, prostate, melanoma, head and neck [39-44], lung [45] or pancreatic cancers [45, 46]. Interestingly, statin treatment was associated with a reduced number of colon adenomatous polyps, including advanced forms, and a smaller size, suggesting that the beneficial effects of statins could originate early in the course of tumor progression [47]. A preclinical model of liver carcinogenesis showed that lovastatin reduced the number of tumor nodules, an effect that was partially antagonized by supplementation with ubiquinone. This occurred in absence of modification in cholesterol levels, suggesting that cholesterol shortage is not responsible for the sensitivity to statins, as also observed in many experimental in vitro systems (see above) [48]. Interestingly, it has been proposed to take advantage of the anti-inflammatory properties of statins to oppose the deleterious effects of ionizing radiation (IR), including normal tissue fibrosis [49]. Statins can indeed restrict IR-induced NFkB activation, which promotes expression of inflammatory cytokines [50,51]. In addition, statins were shown to improve radiation-induced intestine injury $[52,53]$, among other effects like promotion of double DNA strand breaks repair. 


\section{2-Experimental cancer models: the promise of statins}

Many studies have reported the cytotoxic effects exerted by statins in various experimental setups. Strikingly, although direct toxicity to normal cells from the muscle [54] or the endothelia was reported, most normal cell types are largely unaffected by statins [44, 5558]. By contrast, strong toxicity is induced in many diverse cancer cells, and quite often results in apoptosis. This preferential activity towards cancer cells has made statins good candidates to target these cells and drive them to undergo programmed cell death. Virtually any cancer type, from hematological to solid tumors, has been shown to be sensitive to statins. Within the scope of this review, we will mostly focus on digestive cancers, and we certainly apologize for not referring to some of the very numerous articles in the field.

\subsection{1-Pancreatic cancer}

Pancreatic cancer, which is much deadly, has been the subject of several studies. Pancreas tumor cell invasion in vitro, and liver metastasis from xenografts in mice were reduced or prevented by fluvastatin, and rescued in vitro with all-trans-geranyl-geraniol. The in vitro suppression effect was associated with a blockade of RhoA translocation from the cytosol to the membrane fraction, thereby reducing its GTPase activity [59]. In addition, fluvastatin treatment of MIAPaCa-2 cells with a codon 12 mutant p21ras induced apoptosis, which was prevented by the addition of mevalonic acid. Fluvastatin induced deoxycytidine kinase, the enzyme responsible for gemcitabine activation. Consequently, the addition of both fluvastatin and gemcitabine was even more potent at triggering cell apoptosis, and reducing tumor growth in animals [60]. Importantly, this latter study suggests that tumors carrying activating ras mutations could also be treated by statins. The various statins were also described to induce, to different extents, the death of CAPAN-2, BxPc-3 and MiaPaCa-2 cells, simvastatin being the most potent in vitro, and rosuvastatin in vivo. This strong toxicity was always associated with impairment of ras translocation to the plasma membrane [61]. The Akt/PKB and/or the NFKB and Raf/MEK survival pathways were inhibited by atorvastatin in Panc-1 and MiaPaCa-2 cells, which sensitized the cells further to combinations with gemcitabine and 5-Fluorouracile. These responses were dependent on expression of the 
P2X7 purinergic receptor [62]. Finally, simvastatin was a much stronger inducer of cell toxicity than pravastatin, as shown by cell rounding and MTT assays [63].

\subsection{2-Gastric cancer}

As other highly deadly cancers, gastric and esophageal cancers have also been challenged with statins. The gastric carcinoma TE-8 and SKGT-4 cell lines were shown to be sensitive to lovastatin, which suppressed viability and invasion, effects paralleled with reduced expression of ErK1/2, c-Jun and COX-2. However, lovastatin did not prevent tumor growth in mouse xenografts. We have shown recently that several statins, but not pravastatin, triggered strong levels of apoptosis in the gastric cancer HGT-1 cell line, effects prevented very efficiently by addition of geranyl geranyl pyrophosphate, mevalonate and, to a lower extent, by farnesyl pyrophosphate or cholesterol [64]. In addition, lovastatin induced procaspase-7 in a transcriptional manner, as it did for caspase- 2 in other digestive cell lines [64], indicating that these caspases could be important drivers of the cytotoxic response elicited in cancer cells. Furthermore, statin-adapted HGT-1 cells grew more slowly in vitro and in vivo when transplanted into immuno-compromised mice, suggesting that adaptation to statins could lower tumor growth in this model [65].

\subsection{3-Liver cancer}

Apoptosis was triggered in Huh-7 and HepG2 HCC cell lines by fluvastatin, together with G0/G1 cell cycle arrest, and a down-regulation of the ERK1/2 and an up-regulation of the MAP Kinase pathways [66]. These effects were further amplified when statins were combined with activators of the benzodiazepine receptors, which are often up-regulated in tumors, and could overcome chemoresistance imposed by overexpression of Bcl-2 [67-69]. Pravastatin was much less active, and required, as in many if not all other cell models, very high concentrations (above $250 \mu \mathrm{M}$ ) to manifest some pro-apoptotic effects that were somewhat magnified by benzodiazepine receptor activators. In addition, co-treatments of HepG2 cells with EPA and lovastatin, two separate classes of HMG-CoA reductase inhibitors, amplified cell growth arrest, as compared to lovastatin alone [70]. Another study showed, using the same cell lines, that simvastatin induced apoptosis, G0/G1 cell cycle arrest, suppressed CDKs and up-regulated p19 and p27 [71]. The authors further showed that simvastatin suppressed cell adhesion, paralleled by a decrease of B1, B2 and A3 integrins 
and a strong suppression of ROCK-I in these cell lines [71]. Treatment of Huh-7 HCC cells by lovastatin induced apoptosis, an effect that was further amplified by enzastaurin, a PKC- $\beta$ inhibitor, in a strategy developed to counteract the inductive effect of lovastatin on this enzyme [72]. In addition, tumors from MH134 cells barely developed in immune-competent mice administered this drug combination. In another study, atorvastatin suppressed Mycdriven proliferation of human Huh-7 and HepG2 cells in vitro and Myc-induced HCC in transgenic mice, effects that were correlated with the blockade of Myc phosphorylation, a step catalyzed by Rac and necessary for its tumor-promoting activity, and being suppressed by the statin [73]. Simvastatin triggered apoptosis of Hep3B and HepG2 liver cancer cells, but no direct correlation between the rates of cell death and the level of HMG-CoA reductase activity was observed [63]. It was also demonstrated that the lack of cytotoxic effect of the hydrophilic pravastatin was likely due to a poor uptake of the drug by cancer cells, which do not express the OATP1B1 specific transporter, whereas lipophilic statins enter the cells readily. Geraniol and simvastatin, added at sub-active concentrations, triggered HepG2 cells apoptosis [74]. The induction of apoptosis by simvastatin in HepG2 cells was associated with some induction of the pro-apoptotic BAX gene, and a mild reduction in the anti-apoptotic $\mathrm{BCL}-2$ gene, suggesting that pre-translational events could also participate in the cytotoxic response of liver cells to statins [75]. Importantly, pravastatin was shown to suppress lung metastasis from HCC in a rat model, further suggesting a preventing effect of statins against cancer spreading [76].

\subsection{4-Colon cancer}

Several colon cancer cell lines (SW480, HCT116, LoVo and HT-29) were shown to be highly sensitive - albeit to various degrees - to apoptosis induction by lovastatin, an effect accompanied by reduction of the anti-apoptotic $\mathrm{Bcl}-2$ and a rise of the pro-apoptotic Bax proteins [77]. The same investigators demonstrated that the addition of GGPP, but not FPP, fully prevented lovastatin-induced apoptosis. Furthermore, lovastatin strongly potentiated the death induction by 5-FU or cisplatin. This was quite remarkable for HT-29 cells, which were otherwise barely affected by lovastatin alone. In both Ras wt and Ras mutant rat intestinal cells, lovastatin triggered apoptosis [77]. This was associated with a decrease in the membrane bound RhoA and RhoB proteins, indicating that blunting the activity of membrane-bound Rho proteins was responsible for the apoptotic effects of the statin. In 
addition, simvastatin and lovastatin sensitized SW480 cells to Trail-induced apoptosis, presumably upon increasing the fraction of cells arrested in G0/G1 [78]. CRC cell lines, either sensitive or resistant to 5-FU, were readily pushed into apoptosis by cerivastatin, with up to 310-fold increase in sensitivity, as compared to 5-FU alone [79]. Cerivastatin suppressed NF$\mathrm{kB}$ transcriptional activity, which is otherwise responsible for the induction of anti-apoptotic genes. Mevastatin blocked the progression of HCT116 cells into the cell cycle through activity of the cell cycle inhibitor p21. Cells with inactive p21 were insensitive to mevastatin [80]. In addition, lovastatin suppressed the adhesion of HT29 cells to endothelial cells, an effect driven by E-selectin, which expression was suppressed by lovastatin, lending support to the notion that statins may reduce metastases [81]. In a tumor prevention scheme, the addition of atorvastatin reduced the occurrence of adenomatous polyps by $70 \%$ in the $\mathrm{APC}^{\mathrm{min} /+}$ mouse model of colon carcinogenesis. This effect was further increased in combining atorvastatin and celecoxib. As a response to treatment, apoptosis was readily manifested in the adenocarcinomas in response to either drug or the combination [82]. However, conflicting results were also reported with the same mouse model, where atorvastatin was efficient at reduced tumor growth but not polyp formation [83]. These discrepancies could likely be attributed to other effects linked, for example, to the types of diet that differed between the two studies. Nevertheless, a recent study with pitavastatin in the Min model also reported a reduced number of colon polyps [84]. This was associated with a drop in the expression of cyclooxygenase-2, IL6, iNOS, MCP-1 and Pai-1 in the healthy part of the colon. Among these effects, only iNOS expression was also detected in polyps, providing evidence for an anti-inflammatory effect of statins in pre-cancerous lesions. In another study, the atorvastatin+celecoxib combination induced p21 ${ }^{\mathrm{Cip} 1 / \mathrm{Waf} 1}, \mathrm{p} 27^{\mathrm{Kip} 1}$, and phospho-JNK, decreased the levels of phospho-AKT and hyper-phosphorylated Rb. It also selectively modified membrane localization of small G proteins (RhoA-C) [85]. CRC cell lines were analyzed for their content in the bone morphogenetic factor 2 (BMP2), in relation to their sensitivity to statins. It was found that cells expressing high levels of the protein in response to statins (SAOS2, HCT116, DLD1) were much more sensitive to apoptosis induction than cells (HT-29, SW480) in which the BMP pathway was not activated by statins [86]. Activation of the BMP pathway was associated with high expression of SMAD4, which suppression blocked activation of the pathway. Only tumors from statin-sensitive cell lines grown in mice were growth-inhibited by simvastatin. These data suggested that statin- 
induced cell death in CRC cell lines was strongly dependent on activity of the BMP pathway. Recently, it was shown that the BMP2 gene promoter was methylated in cell lines with the hypermethylator phenotype and in tumors [87]. Interestingly, statins could up-regulate expression of the DNA methyl transferase, leading to demethylation of the BMP2 and other genes, thereby inducing the transition from a stem-like cell to a more differentiated phenotype. This effect was accompanied by a rise in sensitivity to 5-FU. Tumor growth in mice was also reduced by statins as a result of recovery of BMP2 expression. In another study, simvastatin triggered apoptosis of COLO-205 and HCT116 CRC cell lines, together with a decrease of $\mathrm{Bcl}-2, \mathrm{Bcl}-\mathrm{xL}, \mathrm{ClAP} 1$ and $\mathrm{c}-\mathrm{FLIP}$. Tumors in mice showed increased apoptosis, larger necrotic areas, and reduced angiogenesis, all effects being associated with reduced tumor growth, in response to simvastatin [88]. In addition, it was shown that lovastatin suppressed survivin expression through antagonism of the Pi3K pathway, presumably ensuing from blockade of ras farnesylation, in SW480 cells [89]. A recent study surveyed the sensitivity to apoptosis as a function of KRAS mutations in CRC cell lines. Hence, low doses of simvastatin $(0.2 \mu \mathrm{M})$ sensitized KRAS mutant cell lines (including LOVO and SW480), but not $\mathrm{BRAF}^{\mathrm{V} 600 \mathrm{E}}$ mutants (like HT29), which may be associated with cetuximab resistance [90]. The association of simavastatin and cetuximab, although a more powerful cell death inducer than any drug alone on KRAS mutants, did not sensitize BRAF mutant cells in vitro or in vivo in mice. Hence, simvastatin may overcome cetuximab resistance, depending on the presence of BRAF mutations, in KRAS mutant CRC cells. Finally, a bioinformatics analysis of statin data throughout the $\mathrm{NCl} 60$ cell line panel identified genes involved in the resistance to lovastatin and simvastatin using SNP mapping [91]. The data, confirmed in RNAi experiments, identified genes distinctively involved in resistance to either simvastatin or lovastatin. Only the EAF2 gene was common between the two statins, the silencing of which restored sensitivity of HCT116 cells to both statins, thereby validating the pharmacogenomics approach. Nevertheless, EAF2 silencing did not sensitize the chemotherapy resistant HT29 CRC cell line. In addition, lovastatin was shown to inhibit histone deacetylase activity, leading to the stimulation of $\mathrm{p} 21^{\mathrm{WAF} / \mathrm{CIP}}$-dependent transcription. The effect was as pronounced as that observed in response to trichostatin A or valproic acid, two bona fide histone deacetylase inhibitors [38].

\section{3-Cancer treatment: human trials}


In view of the compelling pre-clinical evidence that mevalonate restricting agents, like statins, may help prevent but, more probably, treat cancer, a number of prospective studies are underway, or will soon be, as recorded by the clinicaltrials.gov web site. As of November 2, 2012, interrogating "statins" AND "cancer" yields 66 entries related to cancer; among these, 13 for breast, 12 for hematological diseases, 9 for prostate, 9 for CRC, 8 for lung, 3 for liver, 2 for gynecological cancers, 2 for gastric cancer, 2 for melanoma, 1 for pancreas, 1 for bone and 1 for kidney. Hence digestive diseases account for 15 trials, CRC being the most represented. Up to now, although several of the trials should be completed, or near completion, no results have been posted. A textual summary of the trials for digestive cancers is presented in Table 1 (adapted form the Clinicaltrials.gov web site).

Disappointingly, statins used as single agents did not demonstrate efficient cure of CRC patients. However, it was observed, in a population of 12000 postmenopausal women under statin therapy for at least 3 years, that CRC incidence was reduced by an average 21 $\%$, without specific effects according to tumor location, stage or grade [92]. Statins reduced by $30 \%$ the incidence of metastasis in patients diagnosed with CRC [47]. In addition, patients under statin treatment for 5 years when they were diagnosed with CRC presented a less advanced form of the disease. A clinical trial associating simvastatin and FOLFIRI suggested that this drug combination could show promise in metastatic CRC [93]. Several additional data, relevant for colorectal cancer, can be found in [94]. In addition, prostate cancer patients had a reduced occurrence of nonorgan confined disease if taking statins at time of prostatectomy, although an effect on cancer recurrence could not be demonstrated [29]. Quite remarkably, patients with advanced liver cancer given pravastatin showed increased survival, from 9 to 18 months, as compared to placebo-treated patients [95]. In addition, as amply supported by the above mentioned studies, combined treatment with statins and anticancer agents is a much more realistic approach, which should allow to readily lower statin doses, and constitutes the basis of the ongoing clinical trials. It seems reasonable to suggest that statins could also be beneficial in an adjuvant setting.

\section{4-Conclusions}

As reviewed here, a lot of experimental data support the idea of using statins in cancer cure 
regimen. As a whole, the benefits of statin use are much higher than the deleterious consequences. It is certainly a strong sign that many clinical trials with cancer patients are underway in several countries. In this respect, it is worth noting that the Francophone Federation of Digestive Oncology is currently testing the use of pravastatin for the treatment of HCC patients in two separate trials: a phase III randomized trial in patients with CHILD A (PRODIGE 11: sorafenib vs sorafenib + pravastatin), in addition to the PRODIGE 21 trial (Table 1). No matter how strong is the experimental evidence in favor of statins, we need these trials to be completed in order to decide to include statins as a new option for the treatment of various cancers. Quite possibly, their association with bona fide anticancer drugs or radiotherapy could lead to use statins in a restricted number of cancers, and in specific sub-populations of patients, taking individual metabolic capacities into account. We believe that the recognition of statins as a real help in cancer treatment will be one among many cases where already pathology targeting drugs may gain novel indications.

Footnote: For additional comprehensive reading on this topic, see the following references:

[1] [3] [96] [97] [98] [2] [99] [100] [101] [102] [103] [104] [39] [105] [46] [106] [23] [94] [24] [107] [108] [55] [109] [110]. 
1. Goldstein, J.L. and M.S. Brown, Regulation of the mevalonate pathway. Nature, 1990. 343(6257): p. 425-30.

2. Demierre, M.F., et al., Statins and cancer prevention. Nat Rev Cancer, 2005. 5(12): p. 930-42.

3. Endo, A., The discovery and development of HMG-COA reductase inhibitors. J Lipid Res, 1992. 33(11): p. 1569-82.

4. Brown, M.S., et al., Induction of 3-hydroxy-3-methylglutaryl coenzyme A reductase activity in human fibroblasts incubated with compactin (ML-236B), a competitive inhibitor of the reductase. J Biol Chem, 1978. 253(4): p. 1121-8.

5. Endo, A., Compactin (ML-236B) and related compounds as potential cholesterollowering agents that inhibit HMG-CoA reductase. J Med Chem, 1985. 28(4): p. 401-5.

6. Quesney-Huneeus, V., M.H. Wiley, and M.D. Siperstein, Essential role for mevalonate synthesis in DNA replication. Proc Natl Acad Sci U S A, 1979. 76(10): p. 5056-60.

7. Luskey, K.L., et al., Amplification of the gene for 3-hydroxy-3-methylglutaryl coenzyme A reductase, but not for the 53-kDa protein, in UT-1 cells. J Biol Chem, 1983. 258(13): p. 8462-9.

8. Hancock, J.F., et al., All ras proteins are polyisoprenylated but only some are palmitoylated. Cell, 1989. 57(7): p. 1167-77.

9. Schafer, W.R., et al., Genetic and pharmacological suppression of oncogenic mutations in ras genes of yeast and humans. Science, 1989. 245(4916): p. 379-85.

10. Wolda, S.L. and J.A. Glomset, Evidence for modification of lamin B by a product of mevalonic acid. J Biol Chem, 1988. 263(13): p. 5997-6000.

11. Beck, L.A., T.J. Hosick, and M. Sinensky, Incorporation of a product of mevalonic acid metabolism into proteins of Chinese hamster ovary cell nuclei. J Cell Biol, 1988.

107(4): p. 1307-16.

12. Bellosta, S., R. Paoletti, and A. Corsini, Safety of statins: focus on clinical pharmacokinetics and drug interactions. Circulation, 2004. 109(23 Suppl 1): p. III50-7.

13. Bjornsson, E., E.I. Jacobsen, and E. Kalaitzakis, Hepatotoxicity associated with statins: reports of idiosyncratic liver injury post-marketing. J Hepatol, 2012. 56(2): p. 374-80.

14. Holstein, S.A., et al., Pharmacodynamic effects of high dose lovastatin in subjects with advanced malignancies. Cancer Chemother Pharmacol, 2006. 57(2): p. 155-64.

15. Shepherd, J., et al., Pravastatin in elderly individuals at risk of vascular disease (PROSPER): a randomised controlled trial. Lancet, 2002. 360(9346): p. 1623-30.

16. Strandberg, T.E., et al., Mortality and incidence of cancer during 10-year follow-up of the Scandinavian Simvastatin Survival Study (4S). Lancet, 2004. 364(9436): p. 771-7.

17. Heart Protection Study Collaborative, G., MRC/BHF Heart Protection Study of cholesterol lowering with simvastatin in 20,536 high-risk individuals: a randomised placebo-controlled trial. Lancet, 2002. 360(9326): p. 7-22.

18. Alsheikh-Ali, A.A., et al., Effect of the magnitude of lipid lowering on risk of elevated liver enzymes, rhabdomyolysis, and cancer: insights from large randomized statin trials. J Am Coll Cardiol, 2007. 50(5): p. 409-18.

19. Baigent, C., et al., Efficacy and safety of cholesterol-lowering treatment: prospective meta-analysis of data from 90,056 participants in 14 randomised trials of statins. Lancet, 2005. 366(9493): p. 1267-78.

20. Dale, K.M., et al., Statins and cancer risk: a meta-analysis. JAMA, 2006. 295(1): p. 7480. 
21. Kaye, J.A. and H. Jick, Statin use and cancer risk in the General Practice Research Database. Br J Cancer, 2004. 90(3): p. 635-7.

22. Graaf, M.R., et al., The risk of cancer in users of statins. J Clin Oncol, 2004. 22(12): p. 2388-94.

23. Haukka, J., et al., Incidence of cancer and statin usage--record linkage study. Int J Cancer, 2010. 126(1): p. 279-84.

24. Boudreau, D.M., O. Yu, and J. Johnson, Statin use and cancer risk: a comprehensive review. Expert Opin Drug Saf, 2010. 9(4): p. 603-21.

25. Medina, M.W., et al., Alternative splicing of 3-hydroxy-3-methylglutaryl coenzyme A reductase is associated with plasma low-density lipoprotein cholesterol response to simvastatin. Circulation, 2008. 118(4): p. 355-62.

26. Clendening, J.W., et al., Dysregulation of the mevalonate pathway promotes transformation. Proc Natl Acad Sci U S A, 2010. 107(34): p. 15051-6.

27. Freed-Pastor, W.A., et al., Mutant $p 53$ disrupts mammary tissue architecture via the mevalonate pathway. Cell, 2012. 148(1-2): p. 244-58.

28. Ginestier, C., et al., Mevalonate metabolism regulates Basal breast cancer stem cells and is a potential therapeutic target. Stem Cells, 2012. 30(7): p. 1327-37.

29. Mondul, A.M., et al., Association of statin use with pathological tumor characteristics and prostate cancer recurrence after surgery. J Urol, 2011. 185(4): p. 1268-73.

30. Blais, L., A. Desgagne, and J. LeLorier, 3-Hydroxy-3-methylglutaryl coenzyme A reductase inhibitors and the risk of cancer: a nested case-control study. Arch Intern Med, 2000. 160(15): p. 2363-8.

31. Fritz, G., HMG-CoA reductase inhibitors (statins) as anticancer drugs (review). Int J Oncol, 2005. 27(5): p. 1401-9.

32. Downs, J.R., et al., Primary prevention of acute coronary events with lovastatin in men and women with average cholesterol levels: results of AFCAPS/TexCAPS. Air Force/Texas Coronary Atherosclerosis Prevention Study. JAMA, 1998. 279(20): p. 1615-22.

33. Poynter, J.N., et al., Statins and the risk of colorectal cancer. N Engl J Med, 2005. 352(21): p. 2184-92.

34. Jacobs, E.J., et al., Cholesterol-lowering drugs and colorectal cancer incidence in a large United States cohort. J Natl Cancer Inst, 2006. 98(1): p. 69-72.

35. El-Serag, H.B., et al., Statins are associated with a reduced risk of hepatocellular carcinoma in a large cohort of patients with diabetes. Gastroenterology, 2009. 136(5): p. 1601-8.

36. Shadman, M., et al., Non-steroidal anti-inflammatory drugs and statins in relation to colorectal cancer risk. World J Gastroenterol, 2009. 15(19): p. 2336-9.

37. Singh, H., et al., Long-term use of statins and risk of colorectal cancer: a populationbased study. Am J Gastroenterol, 2009. 104(12): p. 3015-23.

38. Chiu, H.F., et al., Statin use and the risk of liver cancer: a population-based casecontrol study. Am J Gastroenterol, 2011. 106(5): p. 894-8.

39. Hindler, K., et al., The role of statins in cancer therapy. Oncologist, 2006. 11(3): p. 306-15.

40. Shellman, Y.G., et al., Lovastatin-induced apoptosis in human melanoma cell lines. Melanoma Res, 2005. 15(2): p. 83-9.

41. Girgert, R., et al., Growth inhibition of neuroblastoma cells by lovastatin and Lascorbic acid is based on different mechanisms. Cancer Lett, 1999. 137(2): p. 167-72. 
42. Paragh, G., et al., Different anticancer effects of fluvastatin on primary hepatocellular tumors and metastases in rats. Cancer Lett, 2005. 222(1): p. 17-22.

43. Knox, J.J., et al., A Phase I trial of prolonged administration of lovastatin in patients with recurrent or metastatic squamous cell carcinoma of the head and neck or of the cervix. Eur J Cancer, 2005. 41(4): p. 523-30.

44. Dimitroulakos, J., et al., Differential sensitivity of various pediatric cancers and squamous cell carcinomas to lovastatin-induced apoptosis: therapeutic implications. Clin Cancer Res, 2001. 7(1): p. 158-67.

45. Khurana, V., et al., Statins reduce the risk of lung cancer in humans: a large casecontrol study of US veterans. Chest, 2007. 131(5): p. 1282-8.

46. Sassano, A. and L.C. Platanias, Statins in tumor suppression. Cancer Lett, 2008. 260(12): p. 11-9.

47. Siddiqui, A.A., et al., The long-term use of statins is associated with a decreased incidence of adenomatous colon polyps. Digestion, 2009. 79(1): p. 17-22.

48. Bjorkhem-Bergman, L., et al., Lovastatin prevents carcinogenesis in a rat model for liver cancer. Effects of ubiquinone supplementation. Anticancer Res, 2010. 30(4): p. 1105-12.

49. Fritz, G., C. Henninger, and J. Huelsenbeck, Potential use of HMG-CoA reductase inhibitors (statins) as radioprotective agents. Br Med Bull, 2011. 97: p. 17-26.

50. Nubel, T., et al., Lovastatin protects human endothelial cells from killing by ionizing radiation without impairing induction and repair of DNA double-strand breaks. Clin Cancer Res, 2006. 12(3 Pt 1): p. 933-9.

51. Ostrau, C., et al., Lovastatin attenuates ionizing radiation-induced normal tissue damage in vivo. Radiother Oncol, 2009. 92(3): p. 492-9.

52. Wang, J., et al., Simvastatin ameliorates radiation enteropathy development after localized, fractionated irradiation by a protein C-independent mechanism. Int J Radiat Oncol Biol Phys, 2007. 68(5): p. 1483-90.

53. Haydont, V., et al., Pravastatin Inhibits the Rho/CCN2/extracellular matrix cascade in human fibrosis explants and improves radiation-induced intestinal fibrosis in rats. Clin Cancer Res, 2007. 13(18 Pt 1): p. 5331-40.

54. Erl, W., et al., HMG-CoA reductase inhibitors induce apoptosis in neointima-derived vascular smooth muscle cells. Atherosclerosis, 2003. 169(2): p. 251-8.

55. Osmak, M., Statins and cancer: current and future prospects. Cancer Lett, 2012. 324(1): p. 1-12.

56. Kotamraju, S., C.L. Williams, and B. Kalyanaraman, Statin-induced breast cancer cell death: role of inducible nitric oxide and arginase-dependent pathways. Cancer Res, 2007. 67(15): p. 7386-94.

57. Kato, S., et al., Lipophilic but not hydrophilic statins selectively induce cell death in gynaecological cancers expressing high levels of HMGCoA reductase. J Cell Mol Med, 2010. 14(5): p. 1180-93.

58. Gauthaman, K., et al., Comparative evaluation of the effects of statins on human stem and cancer cells in vitro. Reprod Biomed Online, 2007. 15(5): p. 566-81.

59. Kusama, T., et al., 3-hydroxy-3-methylglutaryl-coenzyme a reductase inhibitors reduce human pancreatic cancer cell invasion and metastasis. Gastroenterology, 2002.

122(2): p. 308-17. 
60. Bocci, G., et al., Fluvastatin synergistically enhances the antiproliferative effect of gemcitabine in human pancreatic cancer MIAPaCa-2 cells. Br J Cancer, 2005. 93(3): p. 319-30.

61. Gbelcova, H., et al., Differences in antitumor effects of various statins on human pancreatic cancer. Int J Cancer, 2008. 122(6): p. 1214-21.

62. Mistafa, O. and U. Stenius, Statins inhibit Akt/PKB signaling via $P 2 X 7$ receptor in pancreatic cancer cells. Biochem Pharmacol, 2009. 78(9): p. 1115-26.

63. Menter, D.G., et al., Differential effects of pravastatin and simvastatin on the growth of tumor cells from different organ sites. PLoS One, 2011. 6(12): p. e28813.

64. Gibot, L., et al., Human caspase 7 is positively controlled by SREBP-1 and SREBP-2. Biochem J, 2009. 420(3): p. 473-83.

65. Follet, J., et al., Adaptation to statins restricts human tumour growth in Nude mice. BMC Cancer, 2011. 11: p. 491.

66. Sutter, A.P., et al., Cell cycle arrest and apoptosis induction in hepatocellular carcinoma cells by HMG-COA reductase inhibitors. Synergistic antiproliferative action with ligands of the peripheral benzodiazepine receptor. J Hepatol, 2005. 43(5): p. 80816.

67. Hirsch, T., et al., PK11195, a ligand of the mitochondrial benzodiazepine receptor, facilitates the induction of apoptosis and reverses Bcl-2-mediated cytoprotection. Exp Cell Res, 1998. 241(2): p. 426-34.

68. Ravagnan, L., et al., Lonidamine triggers apoptosis via a direct, Bcl-2-inhibited effect on the mitochondrial permeability transition pore. Oncogene, 1999. 18(16): p. 253746.

69. Decaudin, D., et al., Peripheral benzodiazepine receptor ligands reverse apoptosis resistance of cancer cells in vitro and in vivo. Cancer Res, 2002. 62(5): p. 1388-93.

70. Notarnicola, M., et al., Synergic effect of eicosapentaenoic acid and lovastatin on gene expression of HMGCOA reductase and LDL receptor in cultured HepG2 cells. Lipids Health Dis, 2010. 9: p. 135.

71. Relja, B., et al., Simvastatin modulates the adhesion and growth of hepatocellular carcinoma cells via decrease of integrin expression and ROCK. Int J Oncol, 2011. 38(3): p. 879-85.

72. Kim, W., et al., Synergistic anti-tumor efficacy of lovastatin and protein kinase C-beta inhibitor in hepatocellular carcinoma. Cancer Chemother Pharmacol, 2009. 64(3): p. 497-507.

73. Cao, Z., et al., MYC phosphorylation, activation, and tumorigenic potential in hepatocellular carcinoma are regulated by HMG-CoA reductase. Cancer Res, 2011. 71(6): p. 2286-97.

74. Polo, M.P., R. Crespo, and M.G. de Bravo, Geraniol and simvastatin show a synergistic effect on a human hepatocarcinoma cell line. Cell Biochem Funct, 2011. 29(6): p. 4528.

75. Spampanato, C., et al., Simvastatin inhibits cancer cell growth by inducing apoptosis correlated to activation of Bax and down-regulation of BCL-2 gene expression. Int J Oncol, 2012. 40(4): p. 935-41.

76. Taras, D., et al., Pravastatin reduces lung metastasis of rat hepatocellular carcinoma via a coordinated decrease of MMP expression and activity. J Hepatol, 2007. 46(1): p. 69-76. 
77. Agarwal, B., et al., Lovastatin augments apoptosis induced by chemotherapeutic agents in colon cancer cells. Clin Cancer Res, 1999. 5(8): p. 2223-9.

78. Jin, Z., D.T. Dicker, and W.S. El-Deiry, Enhanced sensitivity of $G 1$ arrested human cancer cells suggests a novel therapeutic strategy using a combination of simvastatin and TRAIL. Cell Cycle, 2002. 1(1): p. 82-9.

79. Wang, W., E. Collie-Duguid, and J. Cassidy, Cerivastatin enhances the cytotoxicity of 5-fluorouracil on chemosensitive and resistant colorectal cancer cell lines. FEBS Lett, 2002. 531(3): p. 415-20.

80. Ukomadu, C. and A. Dutta, p21-dependent inhibition of colon cancer cell growth by mevastatin is independent of inhibition of G1 cyclin-dependent kinases. J Biol Chem, 2003. 278(44): p. 43586-94.

81. Nubel, T., et al., Lovastatin inhibits Rho-regulated expression of E-selectin by TNFalpha and attenuates tumor cell adhesion. FASEB J, 2004. 18(1): p. 140-2.

82. Swamy, M.V., et al., Chemoprevention of familial adenomatous polyposis by low doses of atorvastatin and celecoxib given individually and in combination to APCMin mice. Cancer Res, 2006. 66(14): p. 7370-7.

83. Huang, E.H., et al., Atorvastatin induces apoptosis in vitro and slows growth of tumor xenografts but not polyp formation in MIN mice. Dig Dis Sci, 2010. 55(11): p. 3086-94.

84. Teraoka, N., et al., Inhibition of intestinal polyp formation by pitavastatin, a HMG-CoA reductase inhibitor. Cancer Prev Res (Phila), 2011. 4(3): p. 445-53.

85. Xiao, H., et al., Combination of atorvastatin and celecoxib synergistically induces cell cycle arrest and apoptosis in colon cancer cells. Int J Cancer, 2008. 122(9): p. 2115-24.

86. Kodach, L.L., et al., The effect of statins in colorectal cancer is mediated through the bone morphogenetic protein pathway. Gastroenterology, 2007. 133(4): p. 1272-81.

87. Kodach, L.L., et al., Statins augment the chemosensitivity of colorectal cancer cells inducing epigenetic reprogramming and reducing colorectal cancer cell 'stemness' via the bone morphogenetic protein pathway. Gut, 2011. 60(11): p. 1544-53.

88. Cho, S.J., et al., Simvastatin induces apoptosis in human colon cancer cells and in tumor xenografts, and attenuates colitis-associated colon cancer in mice. Int J Cancer, 2008. 123(4): p. 951-7.

89. Kaneko, R., et al., Survivin down-regulation plays a crucial role in 3-hydroxy-3methylglutaryl coenzyme A reductase inhibitor-induced apoptosis in cancer. J Biol Chem, 2007. 282(27): p. 19273-81.

90. Lee, J., et al., Effect of simvastatin on cetuximab resistance in human colorectal cancer with KRAS mutations. J Natl Cancer Inst, 2011. 103(8): p. 674-88.

91. Savas, S., et al., NCl60 cancer cell line panel data and RNAi analysis help identify EAF2 as a modulator of simvastatin and lovastatin response in HCT-116 cells. PLoS One, 2011. 6(4): p. e18306.

92. Simon, M.S., et al., Prospective analysis of association between use of statins or other lipid-lowering agents and colorectal cancer risk. Ann Epidemiol, 2012. 22(1): p. 17-27.

93. Lee, J., et al., Simvastatin plus irinotecan, 5-fluorouracil, and leucovorin (FOLFIRI) as first-line chemotherapy in metastatic colorectal patients: a multicenter phase II study. Cancer Chemother Pharmacol, 2009. 64(4): p. 657-63.

94. Bardou, M., A. Barkun, and M. Martel, Effect of statin therapy on colorectal cancer. Gut, 2010. 59(11): p. 1572-85. 
95. Kawata, S., et al., Effect of pravastatin on survival in patients with advanced hepatocellular carcinoma. A randomized controlled trial. Br J Cancer, 2001. 84(7): p. 886-91.

96. Vincenzi, B., et al., Statins may potentiate bisphosphonates anticancer properties: a new pharmacological approach? Med Hypotheses, 2003. 61(1): p. 98-101.

97. Mo, H. and C.E. Elson, Studies of the isoprenoid-mediated inhibition of mevalonate synthesis applied to cancer chemotherapy and chemoprevention. Exp Biol Med (Maywood), 2004. 229(7): p. 567-85.

98. Graaf, M.R., et al., Effects of statins and farnesyltransferase inhibitors on the development and progression of cancer. Cancer Treat Rev, 2004. 30(7): p. 609-41.

99. Berstein, L.M., Clinical usage of hypolipidemic and antidiabetic drugs in the prevention and treatment of cancer. Cancer Lett, 2005. 224(2): p. 203-12.

100. Hawk, E. and J.L. Viner, Statins and cancer--beyond the "one drug, one disease" model. N Engl J Med, 2005. 352(21): p. 2238-9.

101. Liao, J.K. and U. Laufs, Pleiotropic effects of statins. Annu Rev Pharmacol Toxicol, 2005. 45: p. 89-118.

102. Sleijfer, S., et al., The potential of statins as part of anti-cancer treatment. Eur J Cancer, 2005. 41(4): p. 516-22.

103. Thiery-Vuillemin, A., et al., Molecularly targeted agents: their promise as cancer chemopreventive interventions. Eur J Cancer, 2005. 41(13): p. 2003-15.

104. Walker, K. and M.F. Olson, Targeting Ras and Rho GTPases as opportunities for cancer therapeutics. Curr Opin Genet Dev, 2005. 15(1): p. 62-8.

105. Brown, A.J., Cholesterol, statins and cancer. Clin Exp Pharmacol Physiol, 2007. 34(3): p. 135-41.

106. Stossel, T.P., The discovery of statins. Cell, 2008. 134(6): p. 903-5.

107. Shimoyama, S., Statins are logical candidates for overcoming limitations of targeting therapies on malignancy: their potential application to gastrointestinal cancers. Cancer Chemother Pharmacol, 2011. 67(4): p. 729-39.

108. Vaklavas, C., Y.S. Chatzizisis, and A.M. Tsimberidou, Common cardiovascular medications in cancer therapeutics. Pharmacol Ther, 2011. 130(2): p. 177-90.

109. Kanwar, S.S., A. Poolla, and A.P. Majumdar, Regulation of colon cancer recurrence and development of therapeutic strategies. World J Gastrointest Pathophysiol, 2012. 3(1): p. 1-9.

110. Thurnher, M., O. Nussbaumer, and G. Gruenbacher, Novel aspects of mevalonate pathway inhibitors as antitumor agents. Clin Cancer Res, 2012. 18(13): p. 3524-31. 


\section{Legends to Figures and Tables}

Figure 1: Simplified view of the cholesterol synthesis pathway, also called the mevalonate pathway. The initial enzymes are shown (in red), together with the metabolites. The prenylating metabolites (farnesyl pyrophosphate, FPP and geranylgeranyl pyrophosphate, GGPP) and the target proteins are shown (in green). HMG-CoA: Hydroxy Methyl Glutaryl Coenzyme A.

Figure 2: Main signal transduction cascades activated in response to growth factors. It is expected that, upon statin treatment, Ras-dependent pathways should be blunted. PLC: Phospholipase C; PKC: Protein Kinase C; MAPK: Mitogen Activated Protein Kinase; MEK: MAPK/Extracellular Regulated Kinase; Pi3K: Phosphatidylinositol Tri-Phosphate Kinase; mTOR: mammalian Target Of Rapamycin. 
Table 1 : Ongoing clinical trials recorded at the National Institute of Health (study results are not yet available)

\begin{tabular}{|c|c|c|c|c|}
\hline & Study Title & Conditions & Intervention & URL \\
\hline Colorectal cancer & $\begin{array}{l}\text { Simvastatin in Colorectal } \\
\text { Surgery } \\
\text { Rosuvastatin in Treating } \\
\text { Patients With Stage I or } \\
\text { Stage II Colon Cancer That } \\
\text { Was Removed By Surgery } \\
\text { Crossover Evaluation of } \\
\text { Effect of Atorvastatin on PK } \\
\text { of Irinotecan in CRC } \\
\text { Patients Receiving FOLFIRI } \\
\text { Atorvastatin, Oligofructose- } \\
\text { Enriched Inulin, or Sulindac } \\
\text { in Preventing Cancer in } \\
\text { Patients at Increased Risk } \\
\text { of Developing Colorectal } \\
\text { Neoplasia } \\
\text { Cetuximab and Simvastatin } \\
\text { in Treating Patients With } \\
\text { Advanced or Metastatic } \\
\text { Colorectal Cancer } \\
\text { Simvastatin and } \\
\text { Panitumumab in Treating } \\
\text { Patients With Advanced or } \\
\text { Metastatic Colorectal } \\
\text { Cancer } \\
\text { Simvastatin + } \\
\text { Cetuximab/Irinotecan in K- } \\
\text { ras Mutant Colorectal } \\
\text { Cancer }\end{array}$ & $\begin{array}{l}\text { Intestinal } \\
\text { Neoplasm|Perioperative } \\
\text { Care } \\
\text { Colorectal } \\
\text { Cancer|Precancerous } \\
\text { Condition } \\
\text { Advanced } \\
\text { Adenocarcinoma of the } \\
\text { Colon or Rectum } \\
\text { Colorectal } \\
\text { Cancer|Precancerous } \\
\text { Condition } \\
\text { Colorectal Cancer } \\
\text { Cancer } \\
\text { Colorectal Cancer } \\
\end{array}$ & $\begin{array}{l}\text { Drug: Simvastatin|Drug: Placebo } \\
\text { Drug: rosuvastatin |Other: placebo } \\
\text { Drug: FOLFIRI.|Drug: Atorvastatin } \\
\text { Dietary Supplement: oligofructose- } \\
\text { enriched inulin|Drug: atorvastatin } \\
\text { calcium|Drug: sulindac|Other: } \\
\text { placebo } \\
\text { Biological: cetuximab|Drug: } \\
\text { simvastatin | Other: laboratory } \\
\text { biomarker analysis } \\
\text { Biological: panitumumab|Drug: } \\
\text { simvastatin | Other: laboratory } \\
\text { biomarker analysis } \\
\text { cetuximab/irinotecan/simvastatin }\end{array}$ & $\begin{array}{l}\text { http://ClinicalTrials.gov/show/NCT01605344 } \\
\text { http://ClinicalTrials.gov/show/NCT00335504 } \\
\text { http://ClinicalTrials.gov/show/NCT01190462 } \\
\text { http://ClinicalTrials.gov/show/NCT01110785 }\end{array}$ \\
\hline
\end{tabular}




\begin{tabular}{|c|c|c|c|c|}
\hline & $\begin{array}{l}\text { Trial of XELIRI/FOLFIRI + } \\
\text { Simvastatin Followed by } \\
\text { Simvastatin Maintenance in } \\
\text { Metastatic Colorectal } \\
\text { Cancer } \\
\text { Phase II Study of } \\
\text { Simvastatin Plus Irinotecan, } \\
\text { Fluorouracil, and } \\
\text { Leucovorin (FOLFIRI) for } \\
\text { Metastatic CRC }\end{array}$ & $\begin{array}{l}\text { Colorectal Cancer } \\
\\
\text { Colorectal } \\
\text { Cancer|Metastasis }\end{array}$ & Drug: Simvastatin & $\begin{array}{l}\text { http://ClinicalTrials.gov/show/NCT01238094 } \\
\text { http://ClinicalTrials.gov/show/NCT00313859 }\end{array}$ \\
\hline Liver cancer & $\begin{array}{l}\text { Sorafenib Tosylate With or } \\
\text { Without Pravastatin in } \\
\text { Treating Patients With Liver } \\
\text { Cancer and Cirrhosis } \\
\\
\text { Palliative Treatment of } \\
\text { Hepatocellular Carcinoma } \\
\text { in Patient With CHILD B } \\
\text { Cirrhosis (PRODIGE 21) } \\
\\
\text { Efficacy and Safety Study of } \\
\text { Sorafenib Plus Pravastatin } \\
\text { to Treat Advanced } \\
\text { Hepatocarcinoma }\end{array}$ & $\begin{array}{l}\text { Liver Cancer } \\
\text { Hepatocellular } \\
\text { Carcinoma|CHILD B } \\
\\
\text { Advanced } \\
\text { Hepatocarcinoma }\end{array}$ & $\begin{array}{l}\text { Drug: pravastatin sodium | Drug: } \\
\text { sorafenib tosylate |Other: } \\
\text { laboratory biomarker } \\
\text { analysis |Other: pharmacogenomic } \\
\text { studies | Procedure: quality-of-life } \\
\text { assessment } \\
\text { Drug: sorafenib | Drug: } \\
\text { Pravastatin | Drug: Sorafenib + } \\
\text { Pravastatin | Other: patients } \\
\text { receiving best supportive care } \\
\text { Drug: Pravastatin }\end{array}$ & $\begin{array}{l}\text { http://ClinicalTrials.gov/show/NCT01075555 } \\
\text { http://ClinicalTrials.gov/show/NCT01357486 } \\
\text { http://ClinicalTrials.gov/show/NCT01418729 }\end{array}$ \\
\hline Gastric cancer & $\begin{array}{l}\text { Trial of XP } \\
\text { (Capecitabine/CDDP) } \\
\text { Simvastatin in Advanced } \\
\text { Gastric Cancer Patients } \\
\text { Study to Evaluate the } \\
\text { Efficacy of Pravastatin on } \\
\text { Survival and Recurrence of } \\
\text { Advanced } \\
\text { Gastroesophageal Cancer }\end{array}$ & $\begin{array}{l}\text { Gastric Cancer } \\
\text { Esophageal } \\
\text { Cancer|Stomach Cancer }\end{array}$ & Drug: Pravastatin & $\begin{array}{l}\text { http://ClinicalTrials.gov/show/NCT01099085 } \\
\text { http://ClinicalTrials.gov/show/NCT01038154 }\end{array}$ \\
\hline Pancreatic & $\begin{array}{l}\text { Trial of Simvastatin and } \\
\text { Gemcitabine in Pancreatic } \\
\text { Cancer Patients }\end{array}$ & Pancreatic Cancer & $\begin{array}{l}\text { Drug: } \\
\text { Gemcitabine+simvastatin |Drug: } \\
\text { Gemcitabine+Placebo }\end{array}$ & http://ClinicalTrials.gov/show/NCT00944463 \\
\hline
\end{tabular}


Footnote: Adapted from the clinicaltrials.gov web site. PK : pharmacokinetics; CRC: colorectal cancer; FOLFIRI : mixture of folinic acid, fluorouracile and irinotecan ; XELIRI : mixture of capecitabine and irinotecan ; CHILD B : Level B of Child-Pugh classification of liver cirrhosis ; CDDP : cisplatin. 


\section{Acetyl-CoA+Acetoacetyl-COA}

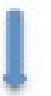

HMG-CoA synthase

HMG-CoA

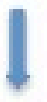

HMG-CoA reductase

Mevalonic Acid



Mevalonate kinase

Mevalonate-5P

I Phosphomevalonate kinase

Mevalonate-5PP

I Mevalonate-5-PP decarboxylase

Isopentenyl-5-PP

FPP synthase

$\downarrow$

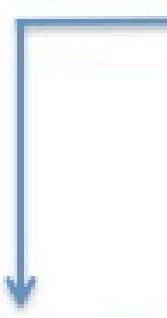

Geranylgeranyl-PP

GGPP Synthase

Prenylated proteins

(Ras, Rho, Rac, Rab, cdc42, lamins)

CHOLESTEROL 




Figure 2 